\title{
Avaliação institucional em Ciências Biológícas nas modalidades presencial e a distância: percepção dos egressos
}

\author{
Dirceu Esdras Teixeira a \\ Luiz Carlos dos Santos Ribeiro ${ }^{a}$ \\ Keila Mara Cassiano a \\ Masako Oya Masuda b \\ Marlene Benchimol ${ }^{c}$
}

\section{Resumo}

O presente artigo apresenta os resultados de uma pesquisa que procurou evidenciar a percepção dos egressos de Cursos de Ciências Biológicas do Estado do Rio de Janeiro como indicador de avaliação institucional. O instrumento de pesquisa utilizado foi um questionário online, composto de perguntas multiopcionais e uma dissertativa. Este foi respondido por 241 egressos, sendo 83 da modalidade de ensino a distância e 158 de ensino presencial. Os resultados revelaram que os egressos do ensino a distância foram os mais satisfeitos em relação à Graduação que cursaram, considerando-a como "ótima". A análise de conteúdo mostrou que a maior insatisfação entre os egressos do Curso presencial foi que o Curso deveria oferecer melhor preparação para o mercado de trabalho. Outros tópicos - necessidade de melhorias na infraestrutura, aumento das atividades práticas em campo, renovação e atualização da grade curricular, e qualidade dos professores - também foram comentados em maior frequência.

Palavras-chave: Egressos. Ciências Biológicas. Avaliação educacional.

\footnotetext{
a Universidade Federal do Rio de Janeiro. Centro de Educação a Distância do Estado do Rio de Janeiro (CEDERJ). Rio de janeiro, Rio de Janeiro, Brasil.

b Fundação CECIERJ. Centro de Educação a Distância do Estado do Rio de Janeiro (CEDERJ). Rio de janeiro, Rio de Janeiro, Brasil.

c Universidade Federal do Rio de Janeiro/Universidade Santa Úrsula/Fundação CECIERJ. Centro de Educação a Distância do Estado do Rio de Janeiro (CEDERJ). Rio de janeiro, Rio de Janeiro, Brasil. 


\section{Introdução}

A opinião do egresso é uma ferramenta importante de acompanhamento da trajetória profissional do aluno graduado, das competências adquiridas durante a Graduação e do panorama de atuação no mercado de trabalho, sendo também, principalmente, uma ferramenta para a melhoria da própria instituição. Pesquisas com egressos são realizadas desde a década de 1930 nos Estados Unidos, com estudos relacionados a opinião dos egressos sobre satisfação no trabalho, relação entre as universidades e o mercado de trabalho, e a transição para o mercado de trabalho. Só na década de 1980 que os estudos expandiram seu foco para investigar as competências adquiridas durante a faculdade (CABRERA; WEERTS; ZULICK, 2005). Essa avaliação institucional, por parte do egresso, pode ser um indicador indispensável de diagnóstico, pois o egresso contará com sua maturidade pessoal e profissional, e um olhar mais globalizado sobre a universidade que o diplomou. Delaney (2000) defende que a experiência dos egressos pode efetivamente auxiliar o Ensino Superior, determinando quais mudanças inovadoras devem ser implementadas para assegurar que os formandos estejam preparados para transformar a realidade do mercado de trabalho. Apesar de sua importância, são poucos os trabalhos que evidenciam a percepção de egressos como indicador de avaliação institucional (MEIRA; KURCGANT, 2009). Dentre os principais trabalhos com egressos do Ensino Superior, destacam-se quatro estudos que avaliaram a percepção de egressos de Cursos de Graduação em Enfermagem: (1) Ghiorzi, Ribeiro e Fenili (1995), sobre a percepção de 13 egressos, inseridos em instituições de saúde em Florianópolis; (2) Soler et al. (2001), que desenvolveram uma pesquisa junto aos egressos do Curso de Enfermagem da Faculdade de Medicina de São José do Rio Preto (FAMERP); (3) Cardoso e Moriya (2003), que avaliaram o processo de formação profissional desenvolvido no Centro de Graduação em Enfermagem (CGE) da Faculdade de Medicina do Triângulo Mineiro (FMTM), segundo a opinião dos egressos, e (4) Oliveira Souza et al. (2011), que avaliaram a opinião de 12 egressos da Faculdade de Enfermagem da Universidade do Estado do Rio de Janeiro. Foram feitos ainda estudos com egressos de Cursos de Pós-Graduação na área de Gerenciamento em Enfermagem da EEUSP (FELLI et al., 2011).

Em outra pesquisa realizada por Lousada e Martins (2005), avaliaram-se as percepções e motivações de dirigentes quanto ao uso de pesquisas com egressos dos Cursos de Ciências Contábeis de nove Instituições de Ensino Superior. O trabalho de Espartel (2009) avaliou a opinião de egressos graduados em uma Instituição de Ensino Superior do Estado de Santa Catarina. O grupo de Câmara e Santos (2012) 
analisou a percepção dos egressos sobre o Curso de Fisioterapia da Universidade Federal de Minas Gerais (UFMG), no período 1982-2005.

Há, ainda, alguns estudos sobre a percepção dos egressos de Cursos de Mestrado Profissional, como o trabalho de Teixeira, Oliveira e Faria (2008), que procuraram avaliar a qualidade do programa de Mestrado Profissional em Administração da PUC Minas/Fundação Dom Cabral. No trabalho de Mendes, Vensceslau e Aires (2010), avaliaram-se os egressos do Programa de Mestrado em Ciências e Saúde da Universidade Federal do Piaú (UFPI) quanto à percepção do Curso, além dos perfis acadêmicos e profissional. Outro grupo (NEPOMUCENO; COSTA, 2012) avaliou a percepção dos egressos do Programa de Mestrado Profissional em Sistemas \& Gestão da Universidade Federal Fluminense quanto ao impacto do Mestrado Profissional no desempenho de seus alunos.

Porém, há poucas informações sobre os egressos dos Cursos de Ciências Biológicas e os poucos estudos existentes são relacionados a relatórios institucionais, não publicados em revistas indexadas. Na literatura analisada, não encontramos estudos que evidenciam a percepção de egressos como indicador de avaliação institucional de Cursos de Ciências Biológicas, formados tanto na modalidade presencial como à distância. $O$ presente trabalho é um primeiro passo nessa direção.

Outro importante aspecto, neste momento, é comparar a avaliação de egressos de diferentes instituições, pública e privada, e a modalidade de ensino, presencial e a distância. Possivelmente, este é um estudo ainda inexistente em nosso país, pois na nossa sociedade ainda há dúvidas quanto à eficácia e à validade do Ensino a Distância (EaD), há desconfiança quanto à possibilidade de se assegurarem qualidade e seriedade aos Cursos, e à qualificação dos profissionais formados nesta implementada modalidade.

Deste modo, é imprescindível - além de um estudo do destino, da inserção no mercado de trabalho e dos reflexos sobre a qualidade de vida dos alunos egressos - ouvir o que os ex-alunos têm a dizer sobre a sua instituição, as dificuldades e as críticas ao sistema, para que as instituições possam se reposicionar, promover mudanças e, enfim, avançar no seu aprimoramento.

Neste contexto, o presente trabalho tem como objetivo evidenciar a percepção dos egressos de cinco Cursos de Ciências Biológicas das modalidades presencial e a distância no Estado do Rio de Janeiro, como uma ferramenta de avaliação institucional visando à melhoria do ensino. 


\section{Metodologia}

A pesquisa foi feita com base em amostras de egressos que concluíram o Curso de Ciências Biológicas, presenciais e a distância, entre os anos de 2005 e 2009, no Estado do Rio de Janeiro. Egressos das seguintes universidades públicas foram pesquisados: Universidade do Estado do Rio de Janeiro (UERJ), Universidade Estadual do Norte Fluminense Darcy Ribeiro (UENF) e Universidade Federal do Rio de Janeiro (UFRJ). Vale a pena ressaltar que estas mesmas universidades oferecem ensino a distância (EaD) através do Consórcio CEDERJ (Centro de Educação Superior a Distância do Estado do Rio de Janeiro). Em relação às instituições privadas, os egressos analisados foram aqueles oriundos da Universidade Santa Úrsula (USU).

Dada a diversidade da amostra no que diz respeito ao tipo de instituição, pública e privada, e à modalidade de ensino, presencial e a distância, a análise será sempre feita distinguindo-se tais características, no intuito de investigar se há diferenças específicas e significativas de percepção dos egressos oriundos das diferentes instituições.

O instrumento de coleta de dados desta pesquisa foi um questionário disponibilizado online, composto por perguntas multiopcionais e uma questão dissertativa. $\mathrm{O}$ contato com os egressos se deu através de listas de e-mails do ambiente virtual de aprendizagem, no caso dos egressos de $\mathrm{EaD}$, e de coordenadores, professores e alunos, ou por comunidades em redes sociais, no caso dos egressos dos cursos presenciais. Primeiramente, foi informado aos egressos o compromisso de sigilo de todos os dados pessoais, oferecendo-se também a opção de total anonimato. Em seguida, enviou-se correspondência eletrônica (e-mail) com o link do questionário para 681 graduados. Destes, somente 241 egressos responderam ao questionário, sendo 83 amostras da modalidade à distância (ex-alunos UENF, UERJ e UFRJ, através do consórcio CEDERJ) e 158 da modalidade presencial, sendo 46 egressos da UENF, 35 da UERJ, 33 da UFRJ e 44 egressos da USU.

Esta técnica de coleta de dados apresenta algumas vantagens, como citadas por Rossi e Slongo (1998):

[...] quando os elementos da amostra se encontram dispersos geograficamente a coleta via questionário pelo correio pode ser recomendável, uma vez que o custo unitário de cada entrevista pessoal tende a ser, nesses casos, muito elevado. Outra situação 
que pode representar vantagem da coleta pelo correio em relação à entrevista pessoal, é quando o número de elementos da amostra é muito alto. Nestes casos o controle da equipe de entrevistadores, necessários para a realização dos trabalhos de campo, pode tornar-se muito complexo e vulnerável (ROSSI; SLONGO, 1998, p. 117).

Outro autor, Malhotra (2001), ressalta ainda outras vantagens neste tipo de coleta de dados através da internet, como: (1) redução da variabilidade de resultados causados pelas diferenças entre os entrevistadores e a codificação; (2) possibilidade de controlar o tempo da pesquisa; (3) garantia do anonimato do entrevistado, e (4) baixo custo. Dessa forma, escolhemos este tipo de pesquisa, pois permite uma abordagem quantitativa, o que melhor se aplica aos objetivos deste estudo.

O teste de Kruskall-Wallis foi utilizado para análise das diferenças entre grupos. Uma vez verificada a não normalidade da distribuição das variáveis quantitativas, utilizou-se, em seguida, o teste de Kolmogorov-Smirnov. Diferenças entre grupos em relação a variáveis qualitativas foram investigadas pelo teste Qui-Quadrado. Para aquelas evoluções antes e depois da Graduação, foi utilizado o teste de Mcnemar-Bowker. Diferenças foram consideradas significativas sempre que os p-valores associados aos testes se apresentassem menores que $5 \%$.

As perguntas do questionário procuraram verificar a satisfação ou a insatisfação dos egressos em relação ao Curso e à infraestrutura da instituição, bem como as competências desenvolvidas durante a Graduação, os fatores positivos considerados facilitadores do exercício profissional e as dificuldades encontradas na prática profissional decorrentes de falhas no Curso de Graduação. Para qualificar a satisfação dos egressos, foi utilizada uma escala de gradação de cinco pontos: muito satisfeito (5), satisfeito (4), indiferente ou neutro (3), pouco satisfeito (2) e nada satisfeito (1). Optou-se por esta escala por ela oferecer alternativas para que o egresso expressasse satisfação total ou parcial, estado indefinido entre satisfação e insatisfação, além de total ou parcial insatisfação. A fim de realizar uma análise numérica da avaliação atribuída a cada quesito, foi definida uma variável descrita "nível de satisfação do item em questão", definida a partir dos conceitos da escala de gradação de satisfação que foram associados a uma escala de 0 a 10 , sendo o conceito "nada satisfeito" relacionado ao valor 0 ; o conceito "pouco satisfeito", relacionado ao valor 10/3 (3,333 ...); o conceito "satisfeito", relacionado ao valor $20 / 3(6,666 \ldots)$, e o conceito "muito satisfeito", relacionado ao valor 30/3, ou seja, o máximo da escala, 10. A resposta indiferente ou neutra 
não foi quantificada para o nível de satisfação, para que tivesse influência neutra nas estatísticas. A definição do nível de satisfação é coerente na escala de 0 a 10 , ao atribuir valor mínimo 0 para o "nada satisfeito", valor máximo 10 para o "muito satisfeito" e intervalo uniforme de tamanho $10 / 3$ para cada item da escala de gradação.

As informações obtidas por meio da pergunta dissertativa foram tratadas quantitativa e qualitativamente, através da técnica de análise de conteúdo, conforme proposta por Bardin (2009). Esta técnica consiste em identificar as categorias de respostas mais relevantes, presentes nas informações brindadas pelas audiências utilizadas na sua obtenção. Após essa fase, foram calculadas as frequências de aparição dessas categorias qualitativas, em termos absolutos e relativos. A investigação quantitativa funda-se na frequência de aparição de determinados elementos da mensagem. Foram considerados apenas os comentários que apresentaram mais de uma citação. Esta concepção pode ser sintetizada nas palavras de Minayo (1998), que afirma: “...O conjunto de dados quantitativos e qualitativos, porém, não se opõem. Ao contrário, se complementam, pois a realidade abrangida por eles interage dinamicamente, excluindo qualquer dicotomia".

\section{Caracterização da amostra}

Em estudo anterior, Teixeira et al. (2014) caracterizaram o perfil e o destino ocupacional da amostra de egressos. Esse estudo mostrou que, para a maioria dos egressos (92,9\%), o Curso de Ciências Biológicas foi o seu primeiro Curso Superior. Somente $6,6 \%$ da amostra já possuía outro Curso Superior e a maioria destes $(5,4 \%)$ era egressa do EaD. Nos cursos presenciais, o número de profissionais que já possuía outra graduação foi mais raro, havendo ocorrências de apenas dois casos na UENF e um na UERJ.

No presente estudo, indagamos sobre o que influenciou a escolha dos egressos pela instituição na qual se formaram. O motivo mais apontado por todos os egressos $(22,9 \%)$ foi "por emitir diploma de universidades conceituadas". A segunda principal influência foi a "qualidade do ensino", com 22,0\%, seguida de "ser um curso gratuito ou barato", com 18,2\%. O quarto motivo mais citado foi a "localização do campus" (ou dos polos, no caso do EaD), assinalado por 13,6\% dos respondentes. Na Tabela 1, são apresentadas as frequências de respostas por instituição. Nota-se que o fato de não ter sido aprovado em outra instituição em que gostaria de estudar pouco influenciou a escolha do egresso pelo CEDERJ $(1,4 \%)$ e não influenciou em nada aquele egresso da UFRJ. 
Tabela 1 - Distribuição dos principais motivos que influenciaram a escolha da Instituição de Ensino

\begin{tabular}{|c|c|c|c|c|c|c|}
\hline & $\mathrm{EaD}$ & UENF & UERJ & UFRJ & USU & Total \\
\hline $\begin{array}{l}\text { Por emitir diploma de universi- } \\
\text { dades conceituadas }\end{array}$ & 48 & 12 & 15 & 22 & 29 & 126 \\
\hline$\%$ & 17,4 & 16,2 & 21,7 & 30,6 & 49,1 & 22,9 \\
\hline $\begin{array}{l}\text { Pela qualidade do ensino } \\
\%\end{array}$ & $\begin{array}{c}47 \\
17,0\end{array}$ & $\begin{array}{c}21 \\
28,4\end{array}$ & $\begin{array}{c}14 \\
20,3\end{array}$ & $\begin{array}{c}28 \\
38,9\end{array}$ & $\begin{array}{c}11 \\
18,6\end{array}$ & $\begin{array}{l}121 \\
22,0\end{array}$ \\
\hline $\begin{array}{l}\text { Por ser gratuito/barato } \\
\%\end{array}$ & $\begin{array}{c}56 \\
20,3 \\
\end{array}$ & $\begin{array}{c}16 \\
21,6\end{array}$ & $\begin{array}{c}12 \\
17,4\end{array}$ & $\begin{array}{c}15 \\
20,8\end{array}$ & $\begin{array}{c}1 \\
1,7\end{array}$ & $\begin{array}{l}100 \\
18,2\end{array}$ \\
\hline $\begin{array}{l}\text { Pela localização do campus/polos } \\
\%\end{array}$ & $\begin{array}{c}40 \\
14,5\end{array}$ & $\begin{array}{c}12 \\
16,2\end{array}$ & $\begin{array}{c}16 \\
23,2\end{array}$ & $\begin{array}{c}1 \\
1,4\end{array}$ & $\begin{array}{c}6 \\
10,2\end{array}$ & $\begin{array}{c}75 \\
13,6\end{array}$ \\
\hline $\begin{array}{l}\text { Por ser um curso a distância } \\
\%\end{array}$ & $\begin{array}{c}35 \\
12,7\end{array}$ & $\begin{array}{c}0 \\
0,0\end{array}$ & $\begin{array}{c}0 \\
0,0\end{array}$ & $\begin{array}{c}0 \\
0,0\end{array}$ & $\begin{array}{c}0 \\
0,0\end{array}$ & $\begin{array}{l}35 \\
6,4\end{array}$ \\
\hline $\begin{array}{l}\text { Por não ter sido aprovado na } \\
\text { universidade que eu gostaria } \\
\%\end{array}$ & $\begin{array}{c}4 \\
1,4 \\
\end{array}$ & $\begin{array}{r}10 \\
13,5 \\
\end{array}$ & $\begin{array}{r}11 \\
15,9 \\
\end{array}$ & $\begin{array}{c}0 \\
0,0 \\
\end{array}$ & $\begin{array}{r}12 \\
20,3 \\
\end{array}$ & 37 \\
\hline $\begin{array}{l}\text { Pela falta de tempo de realizar um } \\
\text { curso regular } \\
\%\end{array}$ & $\begin{array}{r}24 \\
8,7 \\
\end{array}$ & 0,0 & 0,0 & 0,0 & 0,0 & 4,4 \\
\hline $\begin{array}{l}\text { Por trabalhar em horários incom- } \\
\text { patíveis com cursos regulares } \\
\%\end{array}$ & $\begin{array}{l}22 \\
8,0\end{array}$ & $\begin{array}{c}0 \\
0,0\end{array}$ & 0 & 0 & 0 & 4,0 \\
\hline $\begin{array}{l}\text { Por oferecer curso noturno } \\
\%\end{array}$ & $\begin{array}{c}0 \\
0,0 \\
0,0\end{array}$ & $\begin{array}{c}3 \\
4,1 \\
\end{array}$ & $\begin{array}{c}1 \\
1,4\end{array}$ & $\begin{array}{c}6 \\
8,3 \\
\end{array}$ & $\begin{array}{c}0 \\
0,0 \\
\end{array}$ & $\begin{array}{l}10 \\
1,8\end{array}$ \\
\hline $\begin{array}{l}\text { Total } \\
\%\end{array}$ & $\begin{array}{l}276 \\
100\end{array}$ & $\begin{array}{c}74 \\
100\end{array}$ & $\begin{array}{c}69 \\
100 \\
\end{array}$ & $\begin{array}{c}72 \\
100\end{array}$ & $\begin{array}{c}59 \\
100\end{array}$ & $\begin{array}{l}550 \\
100\end{array}$ \\
\hline
\end{tabular}

Fonte: Elaborado pelos autores (2013).

Quando os egressos se autoavaliaram (Tabela 2), em todos os grupos foi típica a classificação como "bom aluno", apontada por 59,3\% dos egressos. Um percentual de $36,9 \%$ da amostra se classificou como "ótimo aluno" e somente $2,9 \%$ se consideraram "aluno regular". A menor frequência de "ótimo aluno" ocorreu entre os egressos da UENF $(23,9 \%)$ e as maiores frequências ficaram entre ex-alunos do $\operatorname{EaD}(43,4 \%)$ e da UFRJ $(42,4 \%)$.

\section{Avaliação institucional}

Com relação à satisfação com a coordenação do curso, a qualificação predominante na amostra foi a de "satisfeito", com 48,5\% dos respondentes. Verificou-se que o egresso do EaD mostrou-se tipicamente "muito satisfeito" e "satisfeito". Dentre os egressos da UFRJ, a resposta mais frequente foi "satisfeito", seguida por "muito satisfeito". Nas instituições UENF, UERJ e USU, a qualificação mais frequente foi "satisfeito" e a segunda mais frequente foi "pouco satisfeito". 
Tabela 2 - Distribuição do conceito de autoclassificação como aluno

\begin{tabular}{l|c|c|c|c|c|c}
\hline \multicolumn{1}{c}{ Autoclassificação como aluno } & EaD & UENF & UERJ & UFRJ & USU & Total \\
\hline Regular & 2 & 1 & 2 & 1 & 1 & 7 \\
\hline$\%$ & 2,4 & 2,2 & 5,7 & 3,0 & 2,3 & 2,9 \\
\hline Bom & 44 & 34 & 21 & 18 & 26 & 143 \\
\hline$\%$ & 53,0 & 73,9 & 60,0 & 54,5 & 59,1 & 59,3 \\
\hline Ótimo & 36 & 11 & 11 & 14 & 17 & 89 \\
\hline$\%$ & 43,4 & 23,9 & 31,4 & 42,4 & 38,6 & 36,9 \\
\hline Não respondeu & 1 & 0 & 1 & 0 & 0 & 2 \\
\hline$\%$ & 1,2 & 0,0 & 2,9 & 0,0 & 0,0 & 0,8 \\
\hline Total & 83 & 46 & 35 & 33 & 44 & 241 \\
\hline$\%$ & 100 & 100 & 100 & 100 & 100 & 100 \\
\hline Fon & & & & &
\end{tabular}

Fonte: Elaborado pelos autores (2013).

Definindo o nível de satisfação numa escala de 0 a 10, a partir dos conceitos da escala de gradação de satisfação, estimaram-se as principais estatísticas do nível de satisfação deste item, conforme citado na Tabela 3. A tabela também exibe os valores relativos (\%) das respostas em que o aluno se declarou "de alguma forma, satisfeito"; neste caso, as respostas "satisfeito" e "muito satisfeito" foram agrupadas. Do mesmo modo, as respostas "pouco satisfeito" e "nada satisfeito" foram agrupadas em "de alguma forma insatisfeito". Apesar de a mediana da avaliação da coordenação do curso mostrar-se igual para todas as instituições, os testes de ANOVA e de Kruskall Wallis foram estatisticamente significativos $(\mathrm{p}$-valor $=0,000)$ nas avaliação da coordenação das cinco instituições. Embora a UFRJ tenha um percentual global maior de "satisfeitos", considerando-se os pesos distintos dos dois conceitos, a coordenação de curso do CEDERJ foi a melhor avaliada, com média 7,6. Os mais descontentes com a coordenação do curso foram os egressos da UERJ e da USU, cujas médias ficaram abaixo de 5,0 . O coeficiente de variação, que infere sobre o grau relativo de dispersão

Tabela 3 - Avaliação do nível de satisfação com a coordenação do curso. C.V.= Coeficiente de Variação

\begin{tabular}{|c|c|c|c|c|c|c|c|}
\hline \multirow[b]{2}{*}{ Instituições } & \multirow[b]{2}{*}{$\mathrm{N}$} & \multicolumn{2}{|c|}{$\%$ Respostas } & \multirow[b]{2}{*}{ Média } & \multirow{2}{*}{$\begin{array}{l}\text { Medi- } \\
\text { ana }\end{array}$} & \multirow{2}{*}{$\begin{array}{l}\text { Desvio } \\
\text { padrão }\end{array}$} & \multirow[b]{2}{*}{ C.V. } \\
\hline & & $\begin{array}{c}\text { De alguma } \\
\text { forma, satisfeito }\end{array}$ & $\begin{array}{c}\text { De alguma } \\
\text { forma, insatisfeito }\end{array}$ & & & & \\
\hline \multicolumn{8}{|l|}{ Coordenação } \\
\hline CEDERJ & 81 & 84,4 & 13,2 & 7,6 & 6,7 & 2,5 & 0,3 \\
\hline UENF & 43 & 65,2 & 28,3 & 6,1 & 6,7 & 2,2 & 0,3 \\
\hline UERJ & 30 & 79,8 & 34,3 & 5,2 & 6,7 & 2,3 & 0,4 \\
\hline UFRJ & 33 & 87,9 & 12,1 & 7,2 & 6,7 & 2,4 & 0,3 \\
\hline USU & 43 & 56,8 & 40,9 & 5,2 & 6,7 & 2,5 & 0,5 \\
\hline
\end{tabular}

Fonte: Elaborado pelos autores (2013). 
global, mostrou que a maior variabilidade de relatos sobre a coordenação do curso ocorreu para a USU.

Quando indagados sobre as instalações físicas, os egressos do EaD e da UENF se mostraram mais satisfeitos que os demais, sendo a resposta típica "satisfeito", com 48,1\% (EAD) e 58,7\% (UENF) de frequência. Porém, houve uma diferença importante em relação à segunda resposta mais frequente. Entre os egressos do $\mathrm{EaD}, 27,7 \%$ declaram-se "muito satisfeito", enquanto que, na UENF, a segunda resposta mais frequente foi "pouco satisfeito" $(26,1 \%)$.

Entre os egressos da UERJ, da UFRJ e da USU, houve o predomínio da opção "pouco satisfeito". Notou-se insatisfação principalmente na UERJ, em que a segunda resposta mais frequente foi "nada satisfeito", enquanto que, na USU e na UFRJ, foi "satisfeito". Observando-se as frequências das respostas "nada satisfeito" e "pouco satisfeito", verificou-se que os mais insatisfeitos foram os egressos da UERJ, seguidos pelos egressos da UFRJ e da USU, como é indicado nos valores médios e medianos de avaliação listados na Tabela 4. Segundo a média, os egressos do CEDERJ foram os mais satisfeitos com as instalações físicas. A maior diversidade de opiniões ocorreu entre os egressos da UERJ.

$\mathrm{Na}$ análise da satisfação com a localização do campus (polo, no caso do EaD) da instituição, houve um predomínio das respostas "satisfeito" e "muito satisfeito"

Tabela 4 - Avaliação das instalações físicas e da localização das instituições (campus/ polos). C.V.= Coeficiente de Variação

\begin{tabular}{|c|c|c|c|c|c|c|c|}
\hline \multirow[b]{2}{*}{ Instituições } & \multirow[b]{2}{*}{$N$} & \multicolumn{2}{|c|}{ \% Respostas } & \multirow[b]{2}{*}{ Média } & \multirow[b]{2}{*}{ Mediana } & \multirow[b]{2}{*}{$\begin{array}{l}\text { Desvio } \\
\text { padrão }\end{array}$} & \multirow[b]{2}{*}{ C.V. } \\
\hline & & $\begin{array}{l}\text { De alguma forma, } \\
\text { satisfeito }\end{array}$ & $\begin{array}{l}\text { De alguma forma, } \\
\text { insatisfeito }\end{array}$ & & & & \\
\hline \multicolumn{8}{|l|}{ Instalações } \\
\hline CEDERJ & 82 & 75,9 & 22,9 & 6,6 & 6,7 & 2,9 & 0,4 \\
\hline UENF & 46 & 73,9 & 26,1 & 6,3 & 6,7 & 2,1 & 0,3 \\
\hline UERJ & 31 & 2,9 & 85,7 & 2,5 & 3,3 & 1,7 & 0,7 \\
\hline UFRJ & 33 & 33,3 & 66,7 & 4,2 & 3,3 & 1,9 & 0,4 \\
\hline USU & 43 & 43,2 & 54,5 & 4,7 & 3,3 & 2,7 & 0,6 \\
\hline \multicolumn{8}{|l|}{ Localização } \\
\hline CEDERJ & 79 & 86,7 & 8,4 & 7,99 & 10,0 & 2,4 & 0,3 \\
\hline UENF & 44 & 87,0 & 8,7 & 7,27 & 6,7 & 2,2 & 0,3 \\
\hline UERJ & 34 & 91,4 & 5,7 & 7,94 & 6,7 & 2,0 & 0,2 \\
\hline UFRJ & 31 & 36,3 & 57,6 & 4,19 & 3,3 & 2,6 & 0,6 \\
\hline USU & 43 & 93,2 & 4,5 & 8,60 & 10,0 & 2,2 & 0,3 \\
\hline
\end{tabular}

Fonte: Elaborado pelos autores (2013). 
em todas as instituições, com exceção dos egressos da UFRJ (42,4\%), que declaram estar "pouco satisfeitos" com a localização do campus da instituição. O maior índice foi encontrado entre os egressos da USU, com 63,6\% de "muito satisfeitos". Tal dinâmica se reflete nos valores médios e medianos exibidos na Tabela 4. A localização do campus da UFRJ recebeu média 4,2 na avaliação, com desvio padrão de 2,6 , resultando num alto coeficiente de variação de $61 \%$. Os testes de ANOVA e de Kruskall Wallis acusaram que as diferenças observadas nas avaliações das instalações físicas e da localização dos campus/polos das cinco instituições foram estatisticamente significativas $(\mathrm{p}$-valor $=0,000)$ para ambas as avaliações.

\section{Desempenho}

Como principal responsável pelo sucesso no curso, os egressos declararam o próprio esforço e a dedicação $(37,1 \%)$, seguidos da parceria com colegas e da formação de grupos de estudo (19,2\%). Este padrão de ordem é comum para os egressos dos cursos presenciais. Entretanto, entre os egressos do EaD, o segundo fator determinante para o sucesso do curso foi "a ajuda dos professores e tutores", seguida de "o curso ter lhe orientado bem" e da "ajuda dos colegas e grupos de estudo".

Um percentual de $34,0 \%$ dos egressos não demonstrou mais contato com a instituição em que se formaram. Em média, 13,3\% dos egressos trabalhavam na mesma instituição em que cursaram a Graduação. Nove dos 83 egressos do $\mathrm{EaD}$ trabalham na própria instituição, aqui entendida a Fundação CECIERJ, representando uma imersão na própria instituição de 10,8\%. A maior imersão ocorreu nas instituições de ensino presencial, destacando-se o maior percentual de indivíduos (30,3\%), que voltaram à instituição para trabalhar, na UFRJ. O menor percentual encontrado foi o da instituição privada, USU, com apenas $2,3 \%$. De modo surpreendente, a maior parte dos egressos da USU não mostrou relação ou contato com a instituição.

Quando indagados se indicariam o curso que fizeram, apenas 9,1\% não o fariam, como pode ser visto na Tabela 5. Mas, tipicamente, o egresso recomendaria o curso que fez, "com certeza", resposta verificada em $60,2 \%$ dos respondentes. Apenas no grupo da USU esta não foi a resposta predominante e sim a resposta "recomendo com ressalvas" (47,7\%), seguido pela resposta "não recomendo" $(38,6 \%)$, sendo, assim, o curso menos recomendado. O curso $\mathrm{EaD}$ foi o curso mais recomendado sem ressalvas pelos egressos $(84,3 \%)$. Outros $27,8 \%$ 
Tabela 5 - Sobre a indicação do curso que fizeram

\begin{tabular}{l|c|c|c|c|c|c|c}
\hline $\begin{array}{c}\text { Indicaria o Curso de Graduação que } \\
\text { você cursou nesta instituição? }\end{array}$ & CEDERJ & UENF & UERJ & \multicolumn{2}{c}{ UFRJ } & USU & Total \\
\hline Não & 1 & 1 & 2 & 1 & 17 & 22 \\
\hline (\%) & 1,2 & 2,2 & 5,7 & 3,0 & 38,6 & 9,1 \\
\hline Não tenho opinião formada a respeito & 0 & 1 & 0 & 1 & 3 & 5 \\
\hline (\%) & 0,0 & 2,2 & 0,0 & 3,0 & 6,8 & 2,1 \\
\hline Sim, com certeza & 70 & 29 & 22 & 21 & 3 & 145 \\
\hline (\%) & 84,3 & 63,0 & 62,9 & 63,6 & 6,8 & 60,2 \\
\hline Sim, com ressalvas & 11 & 15 & 10 & 10 & 21 & 67 \\
\hline (\%) & 13,2 & 32,6 & 28,6 & 30,3 & 47,7 & 27,8 \\
\hline Não respondeu & 1 & 0 & 1 & 0 & 0 & 2 \\
\hline (\%) & 1,2 & 0,0 & 2,9 & 0,0 & 0,0 & 0,8 \\
\hline Total & 83 & 46 & 35 & 33 & 44 & 241 \\
\hline (\%) & 100 & 100 & 100 & 100 & 100 & 100 \\
\hline Fonte: Elabry
\end{tabular}

Fonte: Elaborado pelos autores (2013).

recomendam com ressalvas o curso que fizeram. Dentre as instituições públicas de ensino presencial, o curso mais recomendado sem ressalvas foi o curso da UFRJ. Delaney (2004), em uma pesquisa com 522 egressos de uma universidade privada no noroeste dos Estados Unidos, revelou que os egressos mais propensos a recomendar o curso para futuros alunos foram os que estavam mais satisfeitos com sua experiência de universidade e de vida social.

Quando indagados se fariam o mesmo curso, o maior percentual de que o fariam e na mesma instituição ocorreu para os egressos da UFRJ (78,8\%); em seguida, em relação a esse item, figuraram os egressos do $\mathrm{EaD}(63,9 \%)$ e da UERJ $(60,0 \%)$. O menor percentual $(31,8)$ ocorreu para os formados na USU. Esta instituição também apresentou o maior percentual de profissionais que declararam que, se pudessem, fariam o mesmo curso, mas em outra instituição $(38,6 \%)$. Nas demais instituições, este percentual não chegou a 6,0\%. Nenhum dos ex-alunos da USU declarou que faria outro curso na mesma instituição. Os egressos desta instituição também lideraram os percentuais de que fariam outro curso, conforme a Tabela 6 , a seguir.

\section{Mercado de trabalho}

Quando questionados se, ao concluir a Graduação, se sentiram preparados para o mercado de trabalho, as respostas mais frequentes foram "sim, bastante preparado" para 34,3\% dos respondentes e "sim, mas razoavelmente" para 31,0\% dos respondentes. 
Tabela 6 - Resposta à questão se faria o mesmo curso na mesma instituição

\begin{tabular}{l|c|c|c|c|c|c|c}
\hline & EaD & UENF & UERJ & UFRJ & USU & Total \\
\hline Faria o mesmo curso e na mesma instituição & 53 & 18 & 21 & 26 & 14 & 132 \\
\hline (\%) & 63,9 & 39,1 & 60,0 & 78,8 & 31,8 & 54,8 \\
\hline Faria o mesmo curso, mas em outra instituição & 2 & 1 & 2 & 1 & 17 & 21 \\
\hline (\%) & 2,4 & 2,2 & 5,7 & 3,0 & 38,6 & 9,5 \\
\hline Faria outro curso, em outra instituição & 6 & 9 & 4 & 1 & 11 & 31 \\
\hline (\%) & 7,2 & 19,6 & 11,4 & 3,0 & 25,0 & 12,9 \\
\hline Faria outro curso, na mesma instituição & 21 & 18 & 7 & 5 & 0 & 51 \\
\hline (\%) & 25,3 & 39,1 & 20,0 & 15,1 & 0,0 & 21,2 \\
\hline Não teria feito curso algum & 0 & 0 & 0 & 0 & 2 & 2 \\
\hline (\%) & 0,0 & 0,0 & 0,0 & 0,0 & 4,5 & 0,8 \\
\hline Não respondeu & 1 & 0 & 1 & 0 & 0 & 2 \\
\hline (\%) & 1,2 & 0,0 & 2,9 & 0,0 & 0,0 & 0,8 \\
\hline Total & 83 & 46 & 35 & 33 & 44 & 241 \\
\hline (\%) & 100 & 100 & 100 & 100 & 100 & 100 \\
\hline Fonte: Elaborat
\end{tabular}

Fonte: Elaborado pelos autores (2013).

No grupo EaD, ninguém se considerou 'não preparado' ao final do curso. De fato, o grupo mais autoconfiante pós-formatura era o grupo de profissionais formados no $\mathrm{EaD}$, em que $71,9 \%$ dos respondentes se achavam 'bastante preparados'. Entre os formados no ensino presencial nas instituições UENF, UERJ e UFRJ, tal proporção foi de apenas $15,2 \%, 17,6 \%$ e $15,1 \%$, respectivamente. Entre profissionais da USU, a proporção de pessoas que se sentiam "bastante preparadas" foi a menor, $11,4 \%$.

Dentro dos grupos, os maiores percentuais de formados que se sentiram despreparados foram para a UFRJ e a USU, e 14,6\% responderam que "não se sentiram preparados" (Tabela 7).

\section{Competitividade}

Quando indagados sobre o quanto se sentiam preparados em relação a outros profissionais (Tabela 8), verificou-se que os egressos da UFRJ foram os mais autoconfiantes e apresentaram as maiores proporções $(69,7 \%)$.

Nas outras instituições, a resposta mais frequente foi "tão bem preparado quanto os demais". Somente $6,8 \%$ dos egressos da USU se acharam melhor preparados que os demais. De modo interessante, o grupo de egressos da USU apresentou o maior percentual de respostas considerando-se "menos preparados que os demais", com 29,5\%. 
Tabela 7 - Sobre a preparação para o mercado do trabalho

\begin{tabular}{l|c|c|c|c|c|c|c|c}
\hline $\begin{array}{c}\text { Sentiu-se preparado para o mercado } \\
\text { de trabalho? }\end{array}$ & \multirow{2}{*}{$\begin{array}{c}\text { EaD } \\
\text { Uim, bastante preparado }\end{array}$} & \multicolumn{2}{c}{ UENF } & \multicolumn{2}{c}{ UERJ } & \multicolumn{2}{c}{ UFR } & \multicolumn{2}{c}{ USU } & \multicolumn{2}{c}{ Total } & $\%$ \\
\hline Sim, mas razoavelmente & 21 & 15 & 14 & 9 & 15 & 74 & 31,0 \\
\hline Sim, mas pouco & 2 & 16 & 9 & 7 & 14 & 48 & 20,1 \\
\hline Não & 0 & 8 & 5 & 12 & 10 & 35 & 14,6 \\
\hline Total & 82 & 46 & 34 & 33 & 44 & 239 & 100,0 \\
\hline
\end{tabular}

Fonte: Elaborado pelos autores (2013).

Tabela 8 - Sobre a preparação em relação a outros profissionais

\begin{tabular}{l|c|c|c|c|c|c}
\hline & EaD & UENF & UERJ & UFRJ & USU & Total \\
\hline Melhor preparado do que eles & 20 & 13 & 11 & 23 & 3 & 70 \\
\hline (\%) & 24,1 & 28,3 & 31,4 & 69,7 & 6,8 & 29,0 \\
\hline Menos preparado do que eles & 1 & 2 & 0 & 0 & 13 & 16 \\
\hline (\%) & 1,2 & 4,3 & 0,0 & 0,0 & 29,5 & 6,6 \\
\hline Não tenho ideia & 2 & 6 & 5 & 0 & 2 & 15 \\
\hline (\%) & 2,4 & 13,0 & 14,3 & 0,0 & 4,5 & 6,2 \\
\hline Tão bem preparado quanto eles & 59 & 25 & 18 & 10 & 26 & 138 \\
\hline (\%) & 71,1 & 54,3 & 51,4 & 30,3 & 59,1 & 57,3 \\
\hline Não respondeu & 1 & 0 & 1 & 0 & 0 & 2 \\
\hline (\%) & 1,2 & 0,0 & 2,9 & 0,0 & 0,0 & 0,8 \\
\hline Total & 83 & 46 & 35 & 33 & 44 & 241 \\
\hline (\%) & 100 & 100 & 100 & 100 & 100 & 100 \\
\hline
\end{tabular}

Fonte: Elaborado pelos autores (2013).

De modo bem sintomático, nenhum egresso da UERJ e da UFRJ se declarou "menos preparado que os demais".

A Tabela 9 mostra uma avaliação do conceito geral atribuído ao curso pelo egresso. Os egressos do $\mathrm{EaD}$ apresentaram os maiores valores considerando o curso como "ótimo", assinalado por $72,3 \%$ dos respondentes. Para os ex-alunos dos cursos presenciais, o conceito típico para o seu curso foi "bom". Somente ex-alunos da USU atribuíram o conceito "ruim" (4,5\%) ao curso de Graduação.

\section{Análise de conteúdo}

A questão dissertativa para livre expressão dos alunos egressos foi: "Há algum outro aspecto da Graduação que você julgue necessário mudar?”. Responderam a esta questão 201 ex-alunos. Os três itens mais comentados foram: "Despreparo para o mercado de trabalho", "Infraestrutura da universidade/polos" e "Atividades 
Tabela 9 - Conceito geral do curso atribuído pelos egressos

\begin{tabular}{|c|c|c|c|c|c|c|}
\hline & $\mathrm{EaD}$ & UENF & UERJ & UFRJ & USU & Total \\
\hline Ótimo & 60 & 14 & 8 & 15 & 4 & 101 \\
\hline (\%) & 72,3 & 30,4 & 22,9 & 45,5 & 9,1 & 41,9 \\
\hline Bom & 22 & 26 & 23 & 17 & 25 & 113 \\
\hline$(\%)$ & 26,5 & 56,5 & 65,7 & 51,5 & 56,8 & 46,9 \\
\hline Regular & 0 & 6 & 3 & 1 & 13 & 23 \\
\hline (\%) & 0,0 & 13,0 & 8,6 & 3,0 & 29,5 & 9,5 \\
\hline Ruim & 0 & 0 & 0 & 0 & 2 & 2 \\
\hline (\%) & 0,0 & 0,0 & 0,0 & 0,0 & 4,5 & 0,8 \\
\hline Não respondeu & 1 & 0 & 1 & 0 & 0 & 2 \\
\hline (\%) & 1,2 & 0,0 & 2,9 & 0,0 & 0,0 & 0,8 \\
\hline Total & 83 & 46 & 35 & 33 & 44 & 241 \\
\hline (\%) & 100 & 100 & 100 & 100 & 100 & 100 \\
\hline
\end{tabular}

Fonte: Elaborado pelos autores (2013).

práticas/campo", que somaram $35,3 \%$ dos relatos. Os resultados referentes a discursos dos egressos que foram submetidos à Análise de Conteúdo com suas respectivas exemplificações seguem descritos a seguir:

Houve maior frequência do tópico "Despreparo para o mercado de trabalho", que foi relatado principalmente por alunos egressos da UFRJ (N=12) e da UENF (7). Nenhuma citação a este tópico foi relatada por egressos do CEDERJ. Os egressos reclamaram que o curso visou a prepará-los mais para a carreira acadêmica, deixando-os com déficit para as outras áreas do mercado de trabalho. Também foi comentado que há pouca ou quase nenhuma reflexão sobre o papel do Biólogo na sociedade, passando somente uma visão muito positivista da Ciência. Um exemplo do discurso segue descrito abaixo:

"Acho que a UFRJ poderia preparar mais os alunos para uma vida não acadêmica, voltada para o mercado de trabalho." (Egresso 93 - UFRJ)

De maneira surpreendente, os egressos da UFRJ se consideraram os mais despreparados para o mercado de trabalho; é um fato curioso, pois, em questão anterior, eles se consideraram mais bem preparados que os demais egressos de outras instituições. Os formados relataram que o curso da UFRJ prepara apenas para a área acadêmica e muitos estariam interessados em trabalhar em empresas, com a análise de impactos ambientais, serem empreendedores, entre outras áreas de atuação. 
Já o segundo tópico de maior insatisfação - "Infraestrutura da universidade/polos" - foi relatado principalmente por nove egressos da USU e sete do CEDERJ. Os egressos reclamaram principalmente dos equipamentos utilizados:

"Os equipamentos utilizados em muitas aulas eram bastante precários." (Egresso 80 - USU)

O terceiro item - "Atividades práticas/campo" - foi citado principalmente como precário por alunos egressos da UENF $(\mathrm{N}=8)$, seguidos por egressos da UERJ $(\mathrm{N}=6)$, do CEDERJ $(\mathrm{N}=4)$ e USU $(\mathrm{N}=4)$ :

"Se tratando de um curso de Ciências Biológicas, acredito que deveríamos ter tido mais saídas de campo, pois só houve uma." (Egresso 103 - UENF)

Nenhum egresso da UFRJ declarou insatisfação com as atividades práticas/campo.

Houve também muitas reclamações referentes à grade curricular. Muitos ex-alunos a consideraram "defasada/desatualizada", sugerindo a inclusão de Biologia Marinha Básica, como disciplina do curso básico, e outras matérias atuais, abordando Direito Ambiental, Gestão Ambiental, entre outras. Foi citado também que deveria haver mais opções de disciplinas eletivas e sugeriram carga horária maior em disciplinas obrigatórias:

"Eu acho que a grade curricular está defasada e antiga, faltando disciplinas como Legislação Ambiental e Direito Ambiental." (Egresso 18 - UFRJ)

Um fato importante a ser considerado é que, em relação à "Melhoria na qualidade dos professores", foram apontados, por alguns egressos da UENF, da UERJ e da USU, problemas, como: pouca preparação do professor; didática ruim; descaso dos professores que, por vezes, colocavam alunos para dar aulas, sem estes serem os alunos de Mestrado, pelo menos, além de, também, pouca integração dos alunos com os professores nas atividades de pesquisa e ensino, e com o dia a dia da sociedade.

"Vejo a necessidade de melhor preparação dos professores e material para pesquisa." (Egresso 109 - USU)

Além destes, outros fatores menos frequentes foram pontuados, conforme apresentados na Tabela 10. 
Tabela 10 - Principais aspectos que poderiam ser mudados nos cursos

\begin{tabular}{|c|c|c|c|c|c|c|c|}
\hline $\begin{array}{l}\text { Há algum outro aspecto de seu Curso de } \\
\text { Graduação que você julgue necessário mudar? }\end{array}$ & CEDERJ & UENF & UERJ & UFRJ & USU & Total & $\%$ \\
\hline Despreparo para o mercado de trabalho & 0 & 7 & 4 & 12 & 2 & 25 & 12,4 \\
\hline Infraestrutura & 7 & 2 & 3 & 3 & 9 & 24 & 11,9 \\
\hline Atividades práticas/campo & 4 & 8 & 6 & 0 & 4 & 22 & 10,9 \\
\hline Inclusão de disciplinas & 0 & 4 & 2 & 6 & 1 & 13 & 6,5 \\
\hline Grade curricular defasada/desatualizada & 0 & 1 & 2 & 8 & 2 & 13 & 6,5 \\
\hline Qualidade dos professores & 0 & 3 & 2 & 0 & 6 & 11 & 5,5 \\
\hline Estágio & 6 & 3 & 0 & 0 & 1 & 10 & 5,0 \\
\hline Tutoria & 9 & 0 & 0 & 0 & 0 & 9 & 4,5 \\
\hline Didática dos professores & 0 & 4 & 1 & 2 & 2 & 9 & 4,5 \\
\hline Avaliação de aprendizagem & 8 & 0 & 0 & 0 & 0 & 8 & 4,0 \\
\hline Qualidade das disciplinas & 0 & 4 & 3 & 0 & 1 & 8 & 4,0 \\
\hline Disciplina da Área Ambiental & 0 & 1 & 1 & 4 & 1 & 7 & 3,5 \\
\hline Preparo apenas para a carreira acadêmica & 0 & 3 & 0 & 3 & 0 & 6 & 3,0 \\
\hline Demora na entrega do diploma & 5 & 0 & 0 & 0 & 0 & 5 & 2,5 \\
\hline Carga horária das disciplinas & 0 & 2 & 3 & 0 & 0 & 5 & 2,5 \\
\hline Administração & 0 & 1 & 2 & 1 & 0 & 4 & 2,0 \\
\hline Iniciação Científica & 3 & 0 & 0 & 0 & 0 & 3 & 1,5 \\
\hline Relacionamento aluno-universidade & 3 & 0 & 0 & 0 & 0 & 3 & 1,5 \\
\hline Coordenação & 2 & 0 & 1 & 0 & 0 & 3 & 1,5 \\
\hline Descaso dos professores & 0 & 0 & 2 & 0 & 1 & 3 & 1,5 \\
\hline Demora na entrega das provas & 2 & 0 & 0 & 0 & 0 & 2 & 1,0 \\
\hline Relacionamento aluno-aluno externo & 2 & 0 & 0 & 0 & 0 & 2 & 1,0 \\
\hline Plataforma & 2 & 0 & 0 & 0 & 0 & 2 & 1,0 \\
\hline Integração com a sociedade & 0 & 0 & 1 & 1 & 0 & 2 & 1,0 \\
\hline Integração alunos-professores & 1 & 0 & 0 & 1 & 0 & 2 & 1,0 \\
\hline
\end{tabular}

Fonte: Elaborado pelos autores (2013).

\section{Conclusões}

A análise dos dados coletados nos permitiu compreender a importância dos egressos na avaliação institucional das diferentes modalidades de ensino. Neste sentido, o aluno egresso, seja do ensino presencial ou à distância, é um público detentor de uma visão diferenciada da instituição, pois, uma vez afastados do processo e dotados de maior experiência e maturidade pessoal e profissional, a perspectiva de análise torna-se ampliada.

Os resultados deste estudo revelaram que os egressos de todas as instituições se autoclassificam como bons alunos, com bom envolvimento nas atividades e boa dedicação aos estudos. No mesmo sentido, foi típica a atribuição do sucesso no curso ao esforço próprio, em todos os grupos. 
Em relação ao mercado de trabalho, os egressos da UFRJ, em sua maioria, se sentiram melhor preparados que os demais, o que foi interessante quando comparado com os resultados da análise de conteúdo, em que se consideraram despreparados para o mercado de trabalho. Os egressos das demais instituições se sentiram tão preparados quanto os profissionais formados em outras instituições.

Ao avaliar as instalações físicas das instituições, verificou-se grande insatisfação dos ex-alunos da UFRJ, da USU e, principalmente, da UERJ. Apenas os ex-alunos do CEDERJ e da UENF mostraram satisfação com as instalações.

Também se declararam "satisfeitos" com a Coordenação do Curso, vigente na época, os formados pela instituição de ensino presencial e os do CEDERJ declararam-se, em sua maioria, "muito satisfeitos" ou "satisfeitos" com a Coordenação do Curso.

Com relação à questão aberta, poucos a responderam. A solicitação mais citada entre os egressos do curso presencial foi que o curso deveria oferecer melhor preparação para o mercado de trabalho. Adicionalmente, melhorias na infraestrutura e aumento das atividades práticas em campo foram assinalados por egressos em todos os grupos, sendo que renovação e atualização da grade curricular, incluindo novas disciplinas e qualidade dos professores também foram comentadas em maior frequência.

Pode-se concluir que a instituição com egressos mais descontentes foi a universidade privada (USU), que mais comumente seria recomendada com ressalvas; e, no caso da questão 'se pudessem voltar', declararam que fariam o curso em outra instituição. Vale ressaltar que, no momento da pesquisa, a USU passava por uma grande crise institucional e, mesmo assim, a maioria dos ex-alunos a considerou como um bom curso. Por outro lado, a instituição com egressos mais satisfeitos foi o CEDERJ, os quais se mostraram os mais satisfeitos com a coordenação de curso e as instalações físicas, recomendaram em grande proporção o curso e classificaram o curso como ótimo, em maior proporção.

Espera-se que percepções, pareceres e críticas dos egressos, relatados na presente avaliação, possam fundamentar projetos institucionais e ser aproveitados como ferramenta gerencial. Espera-se, também, que essa ferramenta, aliada a outros indicadores e processos internos de avaliação institucional, possa constituir um importante diferencial para que as IES envolvidas atinjam seus principais objetivos. 
Finalmente, consideramos importante que estudos semelhantes a este sejam realizados em outros contextos universitários e repetidos no tempo, para que as características, os pontos positivos e negativos possam ser mapeados, possíveis padrões ou fatores globais e locais sejam identificados, e a dinâmica temporal dos parâmetros seja observada, tornando possível verificar as melhorias requisitadas.

\section{Agradecimentos}

Os autores agradecem aos alunos egressos da Fundação CECIERJ/CEDERJ (Centro de Educação a Distância do Estado do Rio de Janeiro), da Universidade Federal do Rio de Janeiro (UFRJ), da Universidade do Estado do Rio de Janeiro (UERJ), da Universidade Estadual do Norte Fluminense Darcy Ribeiro (UENF) e da Universidade Santa Úrsula (USU) pela contribuição e pela participação, ambas indispensáveis para a realização desta pesquisa. Agradecemos ainda à Fundação Carlos Chagas Filho de Amparo à Pesquisa do Estado do Rio de Janeiro (FAPERJ).

\section{Referências}

BARDIN, L. Análise de conteúdo. 4. ed. Lisboa: Edições 70, 2009.

CABRERA, A. F.; WEERTS, D. J.; ZULICK, B. J. Making an impact with alumni surveys. In: WEERTS, D. J.; VIDAL, J. (Ed.). Enhancing alumni research European and American perpectives. San Francisco: Jossey-Bass, 2005. p. 5-17. (New Directions for Institutional Research, 126).

CÂMARA, A. M. C. S.; SANTOS, L. L. C. P. S. Um estudo com egressos do curso de Fisioterapia da Universidade Federal de Minas Gerais (UFMG) - 19822005. Revista Brasileira de Educação Médica, Rio de Janeiro, v. 36, n. 1, p. 5-17, 2012. http://dx.doi.org/10.1590/S0100-55022012000200002.

CARDOSO, R. J.; MORIYA, T. M. Egressos do Centro de Graduação em Enfermagemda Faculdade de Medicina do Triângulo Mineiro: formação e trajetória profissional. Revista Mineira de Enfermagem, Belo Horizonte, v. 7, n. 2, p. 102-110, 2003. 
DELANEY, A. M. Voices of experience: renewing higher education with alumni studies. Tertiary Education and Management, United Kingdom, v. 6, n. 2, p. 137-156, 2000. http://dx.doi.org/10.1080/13583883.2000.9967018.

DELANEY, A. M. Ideas to enhance higher education's impact on graduates lives; alumni recommendation. Tertiary Education and Management, United Kingdom, v. 10, n. 2, p. 89-105, 2004. http://dx.doi.org/10.1080/13583883.2004.9967120.

ESPARTEL, L. B. O uso da opinião dos egressos como ferramenta de avaliação de cursos: ocaso de uma instituição de ensino superior. Revista Alcance, Biguaçu, v. 16, n. 1, p. 102-114, 2009.

FELLI, V. et al. Perfil de egressos da Pós-Graduação stricto sensu na área de Gerenciamento em Enfermagem da EEUSP. Revista da Escola de Enfermagem da USP, São Paulo, v. 45, n. spe, p. 1566-1573, 2011. http://dx.doi.org/10.1590/ S0080-62342011000700005.

GHIORZI, A. R.; RIBEIRO, E. M.; FENILI, R. M. O currículo, o curso e a profissão, na visão de egressos da graduação em enfermagem da UFSC. Texto \& Contexto Enfermagem, Florianópolis, v. 4, p. 69-91, 1995.

LOUSADA, A. C. Z.; MARTINS, G. A. Egressos como fonte de informação à gestão dos cursos de Ciências Contábeis. Revista Contabilidade \& Finanças, São Paulo, v. 16, n. 37, p. 73-84, 2005.

MALHOTRA, N. K. Pesquisa de marketing: uma orientação aplicada. 3. ed. Porto Alegre: Bookman, 2001.

MEIRA, M. D. D.; KURCGANT, P. Avaliação de curso de graduação segundo egressos. Revista da Escola de Enfermagem da USP, São Paulo, v. 43, n. 2, p. 481485, 2009. http://dx.doi.org/10.1590/S0080-62342009000200031. PMid:19655693

MENDES, R. F.; VENSCESLAU, É. O. O.; AIRES, S. A. Percepção sobre o curso e perfil dos egressos do Programa de Mestrado em Ciências e Saúde da UFPI. Revista Brasileira de Pós-Graduação, Brasília, v. 7, n. 12, p. 82-101, 2010.

MINAYO, M. C. S. Pesquisa social: teoria. Método e criatividade. Petrópolis: Vozes, 1998. 
NEPOMUCENO, L. D. O.; COSTA, H. G. Mapeamento de percepções na avaliação dos impactos do mestrado profissional no perfil do seu egresso. Produção, São Carlos, v. 22, n. 4, p. 865-879, 2012.

OLIVEIRA SOUZA, N. V. et al. O egresso de enfermagem da FENF/UERJ no mundo do trabalho. Revista da Escola de Enfermagem da USP, São Paulo, v. 45, n. 1, p. 250-257, 2011. http://dx.doi.org/10.1590/S0080-62342011000100035. PMid:21445516

ROSSI, C. A. V.; SLONGO, L. A. Pesquisa de satisfação de clientes:o estadoda-arte e proposição de um método brasileiro. Revista de Administração Contemporânea, Curitiba, v. 2, n. 1, p. 101-125, 1998. http://dx.doi.org/10.1590/ S1415-65551998000100007.

SOLER, Z. et al. Inserção dos egressos do curso de graduação em enfermagem da Faculdade de Medicina de São José do Rio Preto no mercado de trabalho: parâmetros para a qualidade do ensino. Acta Paulista de Enfermagem, São Paulo, v. 14, n. 1 , p. 37-47, 2001.

TEIXEIRA, D. E. et al. Perfil e destino ocupacional de egressos graduados em Ciências Biológicas nas modalidades a distância e presencial. Ensaio Pesquisa em Educação em Ciências, Belo Horizonte, v. 16, n. 1, p. 67-84, 2014.

TEIXEIRA, D. J.; OLIVEIRA, C. C. G.; FARIA, M. A. Perfil dos egressos do Programa de Mestrado Profissional em Administração da PUC Minas/FDC no período de 2000 a 2005. Revista Economia \& Gestão, Belo Horizonte, v. 8, n. 16, p. 100-118, 2008.

\section{Institutional evaluation of the Biological Sciences course in the distance learning and classroom modalities: perceptions of the graduates Abstract}

This paper aims to highlight the perception of graduates of some Biological Science courses in Rio de Janeiro as an indicator of institutional evaluation. The survey instrument used in this study was an online multiple-choice questionnaire and one discursive question. This survey was answered by 241 graduates: 83 of them from distance learning and 158 from traditional classrooms. The results demonstrated that the distance learning graduates were the most satisfied with 
their graduation, considered as "great". However, the results of content analysis revealed that the greatest dissatisfaction among traditional classroom graduates regarded preparation for the labor market. The second topic requested by the students was improvements in infrastructure, which was pointed by graduates from all institutions. Other topics such as increase of practical activities, curriculum renovation, and quality of teachers were also mentioned.

Keywords: Graduates. Biological Sciences. Educational evaluation.

\section{Evaluación institucional en Ciencias Biológicas en las modalidades de educación presencial y a distancia: percepción de los graduados.}

\section{Resumen}

Este artículo presenta los resultados de una investigación que tuvo como objetivo resaltar la percepción de los graduados en Ciencias Biológicas en el Estado de Río de Janeiro como un indicador de evaluación institucional. Los datos del estudio se han obtenido mediante la aplicación de un cuestionario online, compuesto de varias preguntas cerradas (con respuesta definida) y una abierta, el cual fue respondido por 241 graduados, siendo 83 de educación a distancia y 158 de educación presencial. Los resultados permitieron identificar que los graduados de educación a distancia fueron los que se encontraban más satisfechos en relación con su carrera, considerándola como "óptima". El análisis del contenido mostró que la mayor insatisfacción entre los graduados de educación presencial fue que el curso no ofrecía una mejor preparación para el mercado laboral. Otros tópicos, como la necesidad de mejorar la infraestructura, aumentar las prácticas de campo, renovar y actualizar los planes de estudio, y perfeccionar la calidad del profesorado, también fueron los más frecuentemente comentados.

Palabras-clave: Graduados. Ciencias Biológicas. Evaluación educativa.

\section{Informações dos autores}

Dirceu Esdras Teixeira: Doutorando em Educação, Difusão e Gestão em Biociências pela. E-mail: diresdras@gmail.com

Luiz Carlos dos Santos Ribeiro: Mestrando em Ciências Biológicas (Biofísica) pela. E-mail: luizcarlosdsr@gmail.com 
Keila Mara Cassiano: Doutoranda em Engenharia Elétrica-Métodos de Apoio à Decisão, pela Pontifícia Universidade Católica do Rio de Janeiro. E-mail: keilamath@hotmail.com

Masako Oya Masuda: Doutora em Ciências Biológicas (Biofísica) pela Universidade Federal do Rio de Janeiro. Diretora Acadêmica / Vice Presidente da Fundação CECIERJ. Centro de Educação a Distância do Estado do Rio de Janeiro (CEDERJ). E-mail: masako@cecierj.edu.br

Marlene Benchimol: Doutora em Ciências Biológicas (Biofísica) pela Universidade Federal do Rio de Janeiro. Professora de Biologia Celular pela UFRJ e professora titular da Universidade Santa Úrsula. Docente concursada da Fundação CECIERJ. Centro de Educação a Distância do Estado do Rio de Janeiro (CEDERJ) 